\title{
Review on Antidepressant Medication
}

\author{
Sudhir R. Kaulage ${ }^{1 *}$, Kiran T. Aldar ${ }^{1}$, Rahul P. Jadhav², Prakash D. Jadhav ${ }^{1}$, Vishal D. Yadhav ${ }^{1}$ \\ ${ }^{1}$ Department of Pharmaceutics Arvind Gavali College of Pharmacy, Jaitapur, Satara, Maharashtra, India \\ ${ }^{2}$ Department of Pharmaceutics, Rajarambapu College of Pharmacy, Kasegaon, Maharashtra, India \\ Corresponding Author E-mail:- kaulagesudhir@gmail.com
}

\section{ABSTRACT}

Depression is a life-threatening, debilitating, and common disease affecting different segments of community. Chemical and synthetic drugs available to treat this disease cause many adverse effects and may lead to complete recovery in only 50\% of patients. Antidepressants are effective and accessible treatment options that can reduce suffering and prevent relapse of symptoms. They are recommended as first line treatment options in moderate and severe depression or mild or sub threshold depression that has persisted despite other interventions All current antidepressants, with the exception of agomelatine, increase the transmission of the monoamines, particularly serotonin, nor adrenaline and dopamine. The antidepressants are crucial for the treatment of depressive episodes in the acute phase when untreated symptoms are at their worst. With longterm use, however, the brain sets to work compensating for the drug-induced changes with a process he calls oppositional tolerance. Antidepressant drugs are the mainstay for the treatment of depression. Usually, antidepressants are given in combination with some form of limited supportive psychotherapy.

Keywords: Antidepressant medication, Noradrenaline reuptake inhibitors, Depression, Neurotransmitter.

\section{INTRODUCTION}

Antidepressants are drugs used for the treatment of major depressive disorder and of other conditions, including some anxiety disorders, some chronic pain conditions (off-label use), and to help manage some addictions.[1] Depression is a common and recurrent disorder accounting for significant morbidity and mortality worldwide. Depression affects approximately 8-12 per cent of the global population and is currently the leading cause of disability worldwide (in terms of total years lost due to disability). [2] Following a first episode of depression, 22 per cent of sufferers will continue to have symptoms after a year and up to 85 per cent will have two or more episodes despite active treatment. Having longer and more frequent episodes, being single, having a low income and old age all worsen the prognosis. ${ }^{[3,4]}$ Antidepressants are effective and accessible treatment options that can reduce suffering and prevent relapse of symptoms. They are recommended as first line treatment options in moderate and severe depression or mild or sub threshold depression that has persisted despite other interventions. Anti - depressants are not first-line treatment for short duration mild or sub threshold depression or for depression in children and adolescents. ${ }^{[5,6]}$

\section{Pharmacology}

All current antidepressants, with the exception of agomelatine, increase the transmission of the monoamines, particularly serotonin, noradrenaline and dopamine. The majority of antidepressants: selective serotonin reuptake inhibitors (SSRIs), tricyclic antidepressants (TCAs), serotonin and 
noradrenaline reuptake inhibitors (SNRIs), noradrenaline reuptake inhibitors (NRIs) and noradrenaline and dopamine reuptake inhibitors (NDRIs) achieve this by inhibiting the transporter responsible for the re-uptake of one or more monoamines, see Figure 1. Monoamine-oxidase inhibitors (MAOIs) block the mitochondrial enzyme monoamine oxidase, which in turn reduces the breakdown of serotonin, noradrenaline and dopamine. Mirtazapine is an alpha2-adrenoreceptor antagonist that increases noradrenaline and serotonin transmission by reducing the action of the alpha2adrenoreceptor negative feedback pathway. ${ }^{[7]}$ Agomelatine, which is due to be launched in 2009, has a novel mechanism of action namely 5-HT2c and $5-\mathrm{HT} 2 \mathrm{~b}$ antagonism and is a direct agonist at melatonin 1 and 2 receptors. Agomelatine's place in antidepressant therapy is yet to be fully established but it is likely to improve sleep and appears not to cause weight gain or sexual dysfunction, which are often adverse effects of other antidepressants. ${ }^{[8]}$

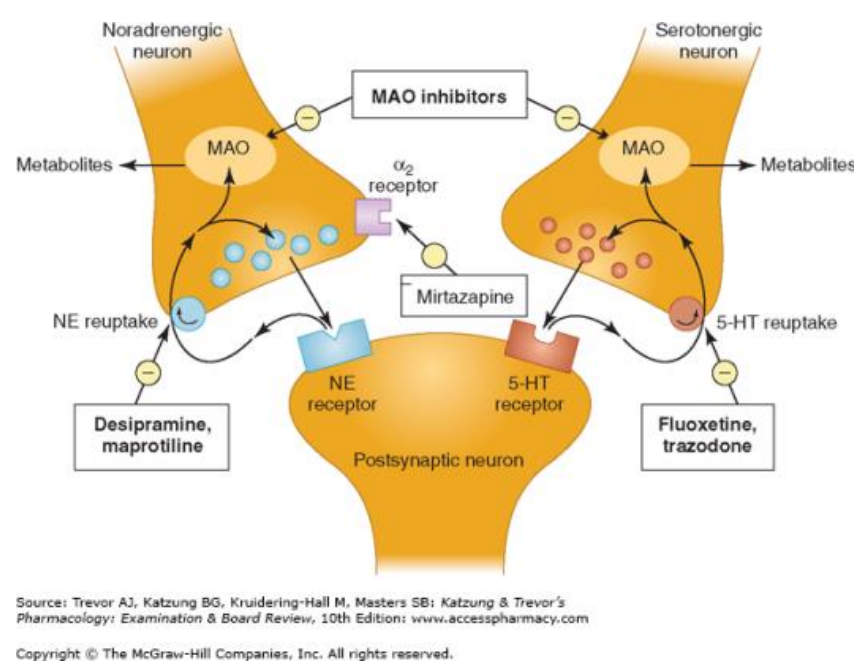

Figure 1. The mechanism behind serotonin and nor adrenaline reuptake inhibition. SNRI: serotonin and noradrenaline reuptake inhibitor; MAO: monoamine oxidase, COMT: catechol-o-methyltransferase

Causes of disease - Environmental factors and Gene
component

\section{Genetic Causes of Depression}

Most of the published genetic association studies of mood disorders have focused on functional polymorphisms (DNA sequence variations that alter the expression and/or functioning of the gene product) in the loci encoding the serotonin transporter (SLC6A4), serotonin 2A receptor (5HTR2A), tyrosine hydroxylase (TH) (the limiting enzyme for dopamine synthesis), tryptophan hydroxylase 1 (TPH1) (serotonin synthesis), and catechol-o-methyltransferase (COMT) (dopamine catabolism. ${ }^{[9]}$ It has long been known that depressive illnesses can run in families, but until fairly recently it was not fully known whether people inherited a susceptibility to these illnesses or if something else such as the environment was the true culprit. Those who research depression have been able to determine that to some extent depressive illnesses can be inherited. What appears to be inherited is a vulnerability to depression. This means that if we have close relatives who have clinical depression, we may inherit a tendency to develop the illness. It does not mean that we are destined to become depressed. ${ }^{[10,11]}$ bipolar disorder is between $50 \%$ and $75 \%$. Brothers and sisters of those with bipolar disorder may be 8 to 18 times more likely to develop bipolar disorder, and 2 to 10 times more likely to develop major depressive disorder than others with no such siblings . ${ }^{[12]}$

Twin Studies: Much of what we know about the genetic influence of clinical depression is based upon research that has been done with identical twins. Identical twins are very helpful to researchers since they both have the exact same genetic code. It has been found that when one identical twin becomes depressed the other will also develop clinical depression approximately $76 \%$ of the time. When 
identical twins are raised apart from each other, they will both become depressed about $67 \%$ of the time. Because both twins become depressed at such a high rate, the implication is that there is a strong genetic influence. If it happened that when one twin becomes clinically depressed the other always develops depression, then clinical depression would likely be entirely genetic. However because the rate of both identical twins developing depression is not closer to $100 \%$ this tells us that there are other things that influence a person's vulnerability to depression. These may include environmental factors such as childhood experiences, current stressors, traumatic events, exposure to substances, medical illnesses, etc. ${ }^{[13]}$ Research has also been done with fraternal twins. Unlike identical twins that have the same genetic code, these siblings share only about $50 \%$ of their genetic makeup and do not necessarily look alike. Studies have shown that when one fraternal twin becomes depressed, the other also develops depression about $19 \%$ of the time. This is still a higher rate of depression when compared to overall rates for the general public, again pointing towards a genetic influence in the development of clinical depression. ${ }^{[14,15]}$

\section{Environmental Causes of Depression}

Environmental causes of depression include events such as stress, traumatic events and childhood difficulties. These are events that can happen to anyone and they happen during our everyday lives. They are considered factors that are outside of us. Some researchers refer to these events as sociological or psychosocial factors because they are a "meeting" or "combination" of events that happen in society and the function and workings of the human mind. Researchers have known for some time that the experiences (events) we have in our lives can and do affect our mental health. Thoughts, emotions and behaviours of people are influenced by the prior experiences in their lives. These experiences can include past relationships, childhood development and past crises. The key to development of clinical depression in some people seems to be how they react to the various environmental causes or factors in their everyday lives. ${ }^{[16]}$

Stress: There appears to be a very complex relationship between stressful situations, the reaction of the individual's mind and body to stress, and the development of clinical depression. Most researchers believe that for some people there is a direct relationship between a stressful event and the development of depression. What is interesting to note is that this stress can be negative or positive. Examples of negative stress are loss of a loved one, loss of a job, loss of a relationship and divorce. Examples of positive stress are planning for a wedding, preparing for a new job, and moving to a new city. Both negative and positive stress from environmental events can precede the development of depression. ${ }^{[17]}$

Traumatic Events: It is a fact that many people have experienced a traumatic event prior to developing depression. Traumatic events in the lives of people include loss of a loved one, a serious medical illness, the end of a marriage or significant financial loss. These types of events can destroy the sense of control and stability in a person's life, often leading to emotional distress. ${ }^{[18]}$

Childhood Difficulties: It has long been known that people with severe difficulties in childhood have higher rates of clinical depression. The most common childhood difficulties include sexual, emotional, or physical abuse, disfunctional upbringing, parental separation, and mental illness in one or both of the parents. One of the most difficult emotional events for a child to endure is the separation or death of a parent before the age of eleven. ${ }^{[19,20]}$ Children that have experienced this event also demonstrate a higher probability of developing depression. 
Synthetic Chemicals: Every day we take in synthetic chemicals from all over. From preservatives, additives and hormones that are found and added to so many of our foods, pesticides that are sprayed and air and water pollution as well. Studies have shown that air and water pollution alone can cause cancer and other diseases. Synthetic chemicals and pollutants are now being more closely looked at as a link to depression and Major Depressive episodes. [21]

Noise Pollution: Noise pollution has been linked to aggression, hypertension, increased stress levels, tinnitus, hearing loss and disruptions in sleep. Specifically, tinnitus is linked to severe depression, panic attacks and forgetfulness. Continual exposure to noise pollution has also been linked to cardiovascular disease and increased blood pressure. A person with possible depressive tendencies will become even more susceptible to depression with continual, prolonged exposure to noise pollution. ${ }^{[22]}$

Electrical Pollution: We are constantly surrounded by radio waves everywhere we go. Much of the electrical equipment we use works off of radio waves and these radio waves have been found to induce depression and rage. The exact causes as to why are not yet known and unlike other types of environmental causes of depression, electrical pollution cannot be seen, heard, tasted, or felt. But, it does have a negative effect on our mind and body. [23] Natural and Catastrophic Disasters: Natural and catastrophic disasters, such as hurricanes, earthquakes, or fires, and even manmade disasters such as bombings and war can push an already susceptible person into a severe Major Depression. [24] The National Centre for Environmental Health has found that people, who normally would not be a candidate for depression, can become depressed after major life altering episodes, such as their house being destroyed in a natural disaster . ${ }^{[25]}$

\section{Adverse effects}

Difficulty tolerating adverse effects is the most common reason for antidepressant Adverse effects discontinuation. ${ }^{[26]}$

General: Almost any medication involved with serotonin regulation has the potential to cause serotonin toxicity (also known as serotonin syndrome) - an excess of serotonin that can induce mania, restlessness, agitation, emotional lability, insomnia and confusion as its primary symptoms. ${ }^{[27,28]}$ Although the condition is serious, it is not particularly common, generally only appearing at high doses or while on other medications. Assuming proper medical intervention has been taken (within about 24 hours) it is rarely fatal. ${ }^{[29,30]}$

\section{Side effects for Prolong Treatment}

The antidepressants are crucial for the treatment of depressive episodes in the acute phase when untreated symptoms are at their worst. With longterm use, however, the brain sets to work compensating for the drug-induced changes with a process he calls oppositional tolerance. The brain tries to re-establish its usual balance of production, release and reuptake of neurotransmitters - as every system of the body does when its normal functioning has been disturbed. The idea is that if the medication artificially jacks up the brain's level of serotonin or norepinephrine, the neurobiology of the system reacts by reducing its own production of the neurotransmitter. For some people, however, stopping the medication has no effect. They continue to have recurring depression. If antidepressant treatment is restored as a response, these patients can develop a permanently recurring illness. This is tardive dysphoria. ${ }^{[31,32]}$

\section{Pharmacotherapy for Depression}

Antidepressant drugs are the mainstay for the treatment of depression. Usually, antidepressants are given in combination with some form of limited supportive psychotherapy. For mild depression, psychotherapy alone may be of use. However, 
evidence is accumulating that the combination of antidepressant treatment and some form of psychotherapy may be superior to either treatment alone, especially for more severe and recurrent depression. ${ }^{[33,34,35]}$ Over the past decade, the so-called tricyclic antidepressants (eg, imipramine or desipramine) have been supplanted by the so-called serotonin selective reuptake inhibitor (SSRI) antidepressants as first-line medications, primarily because of the tolerability and safety of the newer compounds. ${ }^{[36]}$ However, whether the newer antidepressants are more or less efficacious than the older generation compounds, especially for severe depression, is controversial. ${ }^{[37]}$

\section{Classification of Available Antidepressants}

Table 1. Functional Classification of Antidepressants

\begin{tabular}{|c|c|}
\hline Function & Antidepressant \\
\hline $\begin{array}{c}\text { Monoamine } \\
\text { oxidase inhibitor }\end{array}$ & $\begin{array}{c}\text { Isocarboxazid, Phenelzine, } \\
\text { Tranylcypromine }\end{array}$ \\
\hline $\begin{array}{l}\text { Norepinephrine } \\
\text { transport blocker }\end{array}$ & $\begin{array}{l}\text { Amoxapine, Desipramine, } \\
\text { Doxepin, Maprotiline, } \\
\text { Nortriptyline, Protriptyline }\end{array}$ \\
\hline $\begin{array}{c}\text { Serotonin } \\
\text { transport blocker }\end{array}$ & $\begin{array}{c}\text { Amitriptyline, Citalopram, } \\
\text { Clomipramine, Fluoxetine, } \\
\text { Fluvoxamin, Imipramine, } \\
\text { Paroxetine }\end{array}$ \\
\hline $\begin{array}{c}\text { Dopamine } \\
\text { transport blocker }\end{array}$ & Bupropion \\
\hline $\begin{array}{l}\text { Serotonin 5-HT2A } \\
\text { receptor blocker }\end{array}$ & $\begin{array}{c}\text { Mirtazapine, Nefazodone, } \\
\text { Trazodone }\end{array}$ \\
\hline
\end{tabular}

When fewer antidepressant compounds were available, the drugs were classified either as tricyclic antidepressants or as monoamine oxidase inhibitors (MAOIs), a classification that mixes a structural criterion with a functional one. At present, a broad range of structures make up the antidepressant pharmacopoeia, but there are only a few known functional (possibly therapeutic) effects of these compounds. Therefore, a functional classification of antidepressants is more useful than a structural one. Although not a completely satisfactory strategy, all currently available antidepressants can be classified into 1 of 3 classes: (1) MAOIs, (2) biogenic amine neurotransmitters (serotonin, nor epinephrine, and dopamine) reuptake blockers, or (3) serotonin type 2A (5-HT2A) receptor blockers (Table 1). This review focuses on reuptake blockers and 5-HT2A receptor blockers.

\section{IV.CONCLUSION}

Effective treatment and management of depression is a challenge for all healthcare professionals. Antidepressants remain an appropriate treatment for moderate and severe depression, or for mild depression or sub therapeutic depression that has persisted. The SSRIs are recommended first-line because of their superior safety profile and better tolerability. Further antidepressant choices depend in part on adverse reaction profile, interaction potential, the evidence base, pharmacological properties and patient preference. In treatment-resistant cases, a variety of augmentation and combination strategies have been tried with some success. Problems that can occur with antidepressant treatment include an increased risk of bleeding, hyponatraemia, serotonin syndrome and discontinuation symptoms, Antidepressant drugs are the mainstay for the treatment of depression. Usually, antidepressants are given in combination with some form of limited supportive psychotherapy. For mild depression, psychotherapy alone may be of use. 


\section{ACKNOWLEDGEMENT}

Authors are highly Acknowledge the help of teaching staff of Arvind Gavali College of Pharmacy Jaitapur, Satara. For providing necessary information required for review work. Also, we are highly Acknowledge the help and guidance of Dr. Vishal D. Yadhav.

\section{REFERENCES}

[1]. Jennings, Leigh (2018). "Chapter 4: Antidepressants". In Grossberg, George T.; Kinsella, Laurence J. Clinical psychopharmacology for neurologists: a practical guide. Springer. pp. 45-71. Doi: 10.1007/978-3-319-74604-3 4. ISBN 978-3319-74602-9.

[2]. World Health Organization. Mental Health. Depression. http://www.who.int/en/

[3]. Keller MB, Lavori PW, Rice J, et al. The persistent risk of chronicity in recurrent episodes of nonbipolar major depressive disorder: a prospective follow-up. Am J Psychiatry 1986;143:24-8.

[4]. Mueller T, Leon A, Keller M, et al. Recurrence after recovery from major depressive disorder during 15 years of observational follow up. Am J Psychiatry 1999;156:1000-6.

[5]. Anderson IM, Ferrier IN, Baldwin RC, et al. Evidence-based guidelines for treating depressive disorders with antidepressants: A revision of the 2000 British Association for Psychopharmacology guidelines. J Psychopharm 2008;22:343-96.

[6]. National Institute for Health and Care Excellence. Depression in adults. Clinical Guideline CG90. NICE, 2009. http://guidance. nice.org.uk/CG90.
[7]. Artigas F,Nutt D,Shelton R.Mechanism of Action of Antidepressants. Psychopharm Bull 2002;36:(suppl 2):123-31.

[8]. Stahl S. Novel mechanism of antidepressant action: norepinephrine and dopamine disinhibition plus melatonergic agonism. Int J Neuropsychopharm 2007;10:575-8

[9]. Howland R., General health, health care utilization, and medical comorbidity in dysthymia, Int J Psychiatry Med 23, 211-238 (2005) .

[10]. Wells K.B., Burnam M.A., Rogers W., Hays R., Camp P., The course of depression in adult outpatients Results from the Medical Outcomes Study, Arch Gen Psychiatry, 49, 788-794 (2002).

[11]. Williams J.W. Jr, Kerber C.A., Mulrow C.D., Medina A. and Aguilar C., Depressive disorders in primary care: prevalence, functional disability and identification, J Gen Intern Med., 10, 7-12 (2008).

[12]. Wagner R., Burns B.J., Yarnall K., Sigmon A., Walker R. and Gaynes B.N., Minor depression in family practice: functional morbidity, comorbidity, service utilization and outcomes, Psychol Med., 30(6), 1377-1390 (2000).

[13]. Cooper-Patrick L., Crum R.M., Ford D.E., Characteristics of patients with major depression who received care in general medical and specialty mental health settings, Med Care, 32, 15-24 (2009) .

[14]. Paykel E. and Priest R., Recognition and management of depression in general practice, consensus statement, BMJ 305, 1198-1202 (2002).

[15]. Simon G.E., Von Korff M. and Durham M.L., Predictors of outpatient mental health utilization by primary care patients in a health maintenance organization, Am J Psychiatry, 151, 908-913 (2004). 
[16]. Song F., Freemantle N. and Sheldon T.A., et al., Selective serotonin reuptake inhibitors: metaanalysis of efficacy and acceptability, BMJ, 306, 683-687 (2006)

[17]. Kessler R.C., Nelson C.B., McGongale K.A., Liu J., Swartz M. and Blazer DG., Comorbidity of DSMIIIR major depressive disorder in the general population, Results from the US National Comorbidity Survey, Br J Psychiatry, 168, 17-30 (2006).

[18]. Regier D.A., Narrow W.E., Rae D.S., Manderscheid R.W., Locke B.Z. and Goodwin F.K., The de facto US mental and addictive disorders service system, Epidemiologic catchment area prospective 1-year prevalence rates of disorders and services, Arch Gen Psychiatry, 50, 85-94 (2005).

[19]. Pincus H.A., Tanielian T.L. and Marcus S.C., et al., Prescribing trends in psychotropic medications, primary care, psychiatry and other medical specialities, JAMA, 279, 526-531 (2007).

[20]. Simon G.E. and Von Korff M., Recognition, management, and outcomes of depression in primary care, Arch Fam Med., 4, 99-105 (2007).

[21]. Gerber P.D., Barrett J., Barrett J., Manheimer E., Whiting R. and Smith R., Recognition of depression by internists in primary care, a comparison of internist and gold standard psychiatric assessments, J Gen Intern Med,. 4, 7-13 (2003).

[22]. Klinkman M.S., Competing demands in psychosocial care, A model for the identification and treatment of depressive disorders in primary care, Gen Hosp Psychiatry, 19, 98-111 (2001).

[23]. Borowsky S.J., Rubenstein L.V., Meredith L.S., Camp P., Jackson-Triche M. and Wells K.B., Who is at risk of nondetection of mental health problems in primary care, J Gen Intern Med,. 15, 381-388 (2000).

[24]. Linde K., Mulrow C.D. and St. John's wort for depression, Cochrane Review, The Cochrane Library, (2008).

[25]. US Preventive Services Task Force. Guide to Clinical Preventive Services, 2nd ed, Alexandria, Va., International Medical Publishing, (2009).

[26]. Allen, Arthur. "Coping With Side Effects of Depression Treatment" . WebMD. Retrieved 2019-02-04.

[27]. Birmes P, Coppin D, Schmitt L, Lauque D (2003). "Serotonin syndrome: a brief review" . CMAJ. 168 (11): 1439-42. PMC 155963 . PMID 12771076 .

[28]. Boyer EW, Shannon M (2005). "The serotonin syndrome" (PDF). N. Engl. J. Med. 352 (11): 1112-20. doi:10.1056/NEJMra041867 . PMID 15784664 . Archived from the original (PDF) on 18 June 2013.

[29]. Mason PJ, Morris VA, Balcezak TJ (2000). "Serotonin syndrome. Presentation of 2 cases and review of the literature". Medicine. 79 (4): 201-9. doi:10.1097/00005792-20000700000001 . PMID 10941349.

[30]. Sampson E, Warner JP (1999). "Serotonin syndrome: potentially fatal but difficult to recognize" . Br J Gen Pract. 49 (448): 867-8. PMC 1313553 . PMID 10818648.

[31]. Lewinsohn P.M., Seeley J.R., Roberts R.E.and Allen N.B., Center for Epidemiologic Studies Depression Scale (CESD) as a screening instrument for depression among communityresiding older adults, Psychol Aging., 12, 277287 (2007).

[32]. Lustman P.J., Clouse R.E., Griffith L.S., Carney R.M. and Freedland K.E., Screening for depression in diabetes using the Beck 
Depression Inventory, Psychosom Med., 59, 24 (2011).

[33]. Thase ME, Greenhouse JB, Frank E, et al. Treatment of major depression with psychotherapy or psychotherapypharmacotherapy combinations. Arch Gen Psychiatry. 1997; 54:1009-1015.

[34]. Reynolds CF, Frank E, Perel JM, et al. Nortriptyline and interpersonal psychotherapy as maintenance therapies for recurrent major depression: a randomized controlled trial in patients older than 59 years. JAMA. 1999;281:39-45.

[35]. Keller MB, McCullough JP, Klein DN, et al. A comparison of nefazodone, the cognitive behavioral-analysis system of psychotherapy, and their combination for the treatment of chronic depression. N Engl J Med. 2000;342:1462-1470.

[36]. Peretti S, Judge R, Hindmarch I. Safety and tolerability considerations: tricyclic antidepressants vs. selective serotonin reuptake inhibitors. Acta Psychiatr Scand Suppl. 2000;403:17-25.

[37]. Anderson IM. Selective serotonin reuptake inhibitors versus tricyclic antidepressants: a meta-analysis of efficacy and tolerability. J Affect Disord. 2000;58:19-36.

\section{Cite this article as :}

Sudhir R. Kaulage, Kiran T. Aldar, Rahul P. Jadhav, Prakash D. Jadhav, Vishal D. Yadhav, "Review on Antidepressant Medication", International Journal of Scientific Research in Science and Technology (IJSRST), Online ISSN : 2395-602X, Print ISSN : 2395-6011, Volume 6 Issue 2, pp. 580-587, MarchApril 2019. Available at doi :

https://doi.org/10.32628/IJSRST1962118

Journal URL : http://ijsrst.com/IJSRST1962118 